\title{
A Poverty Profile for Rural Botswana
}

\author{
BARBARA WATANABE and EVA MUELLER* \\ University of Michigan, Ann Arbor
}

\begin{abstract}
Summary. - Recognizing that for policy purposes it is important to learn in what ways households that are poor differ from households that have a more adequate income and recognizing that these differences may be cause or consequence of low economic status, this paper compiles a 'poverty profile' of rural Botswana. The data are taken from the Rural Income Distribution Survey conducted in 1975 by the Central Statistical Office of the Government of Botswana - a sample of 950 randomly selected households in 20 rural areas. The survey data enable the authors to determine how close each household comes to meeting its basic requirements.

The paper begins by explaining the derivation of "poverty income ratios'; it then relates the PIRs to the demographic characteristics of households, their education, location and asset holdings. There follows a description of differences in time use and sources of income among the five poverty ratio groups. The authors conclude with a discussion of the implications for policies aimed at the alleviation of poverty.
\end{abstract}

\section{INTRODUCTION}

Development specialists have learned that 'the poor' are not a homogeneous group of people who can all be aided by the same policies. Rather, poor households have a variety of characteristics, and it is necessary to tailor assistance to their specific needs and problems. For policy purposes it is therefore important to learn in what ways households that are poor differ from households that have a more adequate income, recognizing that these differences may be cause or consequence of low economic status. 'Poverty profiles' identify the differentiating demographic and economic features associated with poverty and permit policymakers to design policy accordingly. ${ }^{1}$

Needless to say, the particular traits of poor households depend on the structure of the economy of which they are part. The setting for this investigation is rural Botswana, a peasant economy which has had relatively little exposure to economic and social modernization. Botswana resembles a number of arid Central and West African countries where cattle raising is the major source of income for the rural population. In years when rainfall is adequate, crop cultivation is the second most important source of income. Wage labour is third, followed by hunting and gathering, crafts, professions, trading, food processing, and the like. The mean per capita income at the time of the survey (1975) was Rand 150 , or US $\$ 225$. The Gini coefficient for household income was 0.52 , denoting a high degree of income inequality. One manifestation of rural poverty is a high level of male outmigration from the rural sector to the mines of South Africa and to a few urban centres in Botswana.

This paper is based on data from the Rural Income Distribution Survey (RIDS) conducted in 1975 by the Central Statistical Office of the Government of Botswana. In order to reduce momory error, income data were collected by visiting each household 12 times - once a month over a period of 12 months. In addition questions were asked about time use (in only 5 rounds), assets, and major socioeconomic and demographic characteristics of households. The sample consists of 950 randomly selected households in 20 rural areas. ${ }^{2}$ The survey data enable us to determine how close each household comes to meeting its basic income requirements. Five groups of households were formed, ranging from those which have less than $50 \%$ of a reasonable living standard to those whose income exceeds the standard by more than $50 \%$.

The derivation of 'poverty income ratios' is described in Part 2 of this paper. Part 3 relates the poverty income ratios to the demographic characteristics of households, their education, location, and asset holdings. Part 4 describes differences in time use and sources of income among the five poverty ratio groups. Policy implications are discussed in Part 5.

\footnotetext{
* We are indebted to Kathy Short who participated in the research for this paper.
} 


\section{POVERTY INCOML RATIOS}

The classification of rural households by income relative to basic requirements is based on the rural 'Poverty Datum Line' (PDL) developed by the Central Statistical Office of the Government of Botswana. ${ }^{3}$ The Poverty Datum Line was perceived as the basic minimum need for a decent standard of living among lower income houscholds in the rural areas of Botswana. Estimates were made of amounts of food, clothing, housing, durables, personal care items, cducation, recreation and social duty costs, and taxes for individuals of different age and sex. Added to these were estimated costs of goods required by the houschold as a whole but varying with household size (such as firewood and cooking pots). From these estimated costs an annual Poverty Datum Linc was calculated which varies with household composition.

The next step was to calculate the ratio of Gross Available Income to the Poverty Datum Line. This measure is henceforth referred to as the Poverty Income Ratio (PIR). The Poverty Datum Line or 'minimum income needed for a basic standard of living' was calculated by computing for each single household its income requirements based on its own household composition. Gross Available Income is the total income available to the household after deducting farm and business expenses (excluding depreciation) and taxes, but includes gifts and transfer income. This is the income available to meet household expenses.

After computing this ratio for each household, the five categories shown in Table 1 were formed.

Although the Central Statistical Office described the Poverty Datum Line as 'harsh', some social scientists in Botswana disagreed with that description. ${ }^{4}$ Furthermore, the estimates of Gross Available Income used here exclude the imputed rental value of owned homes. Also, there is no adjustment for underreporting of income (estimated by CSO at $6 \%$, and possibly somewhat higher). For these reasons one should probably view category III, with a PIR of $75-99 \%$, as coming close to meeting basic minimum needs. Categories I and II, with less than $75 \%$, represent genuine poverty groups, while categories IV and V, with PIR's above $100 \%$, represent households clearly above the poverty level.

\section{DEMOGRAPHIC AND SOCIOECONOMIC CHARACTERISTICS OF POVERTY GROUPS}

The first question to be asked is whether poor households differ from better-off ones in houschold size or household composition. Table 2(a) presents a household typology. This typology depicts the structure of the household in terms of the presence of the following age/sex categories:

$\mathrm{E}=$ one or more elderly persons, aged 65 and over

$M=$ one or more males, aged $20-64$

$F=$ one or more females, aged $20-64$

YD = young dependents of either sex, aged $0-19$.

As can be seen from Table 2(a), there is no systematic variation across PIR groups in the frequency of complete three-generational households (elderly person, male and female of prime working age, and young dependents). Complete two-generation households are somewhat less common among the poor than among the more well-to-do. By contrast, households which lack a male of prime working age - whether they are three-generation or two-generation households - account for a relatively large proportion of the bottom PIR groups. Single persons or couples who live alone tend to be well off; poor persons cannot afford to live alone but must join other households. Households containing an elderly person are not necessarily disadvantaged; data not presented here show that such households

Table 1. PIR Categories

\begin{tabular}{llcc}
\hline PIR Categories & $\begin{array}{c}\text { \% Households in } \\
\text { each group }\end{array}$ & $\begin{array}{c}\text { Mean } \\
\text { PIR }\end{array}$ & $\begin{array}{c}\text { Standard } \\
\text { deviation of PIR }\end{array}$ \\
\hline $\begin{array}{l}\text { I. Less than 50\% of income necessary } \\
\text { for basic living standard }\end{array}$ & $22.2 \%$ & $36.4 \%$ & 8.9 \\
II. 50-74\% of income necessary & 15.5 & 62.1 & 6.9 \\
III. $75-99 \%$ of income necessary & 17.2 & 88.2 & 7.4 \\
IV. $100-149 \%$ of income necessary & 19.6 & 120.4 & 13.8 \\
V. $150+\%$ of income necessary & 25.5 & 311.2 & 283.8 \\
\hline
\end{tabular}


Table 2. Distribution of houscholds by demographic characteristics within PIR groups

\begin{tabular}{|c|c|c|c|c|c|c|}
\hline & & & Poverty I & icome Ratio* & & \\
\hline & $0-49 \%$ & $50-74 \%$ & $75-99 \%$ & $100-149 \%$ & $150+\%$ & All \\
\hline (a) Household typology $\dagger$ & & & & & & \\
\hline $\begin{array}{l}\text { Complete 3-generation household } \\
\text { (E-M-F-YD) }\end{array}$ & $9.5 \%$ & $4.2 \%$ & $13.2 \%$ & $11.8 \%$ & $7.2 \%$ & $9.2 \%$ \\
\hline Complete 2-generation household & & & & & & \\
\hline (M-F-YD) & 38.4 & 44.5 & 50.6 & 43.5 & 48.1 & 44.9 \\
\hline $\begin{array}{l}\text { 3-Generation household - no male } \neq \\
\text { (E-F-YD) }\end{array}$ & 16.1 & 9.7 & 9.0 & 14.3 & 3.3 & 10.3 \\
\hline 2-Generation household - no male & & & & & & \\
\hline$(\mathrm{F}-\mathrm{YD})$ & 23.6 & 26.6 & 12.7 & 15.2 & 12.0 & 17.6 \\
\hline Single generation household & 1.3 & 5.3 & 0.7 & 8.4 & 15.1 & 6.7 \\
\hline Other $\S$ & 11.1 & 9.8 & 13.9 & 6.8 & 14.3 & 11.3 \\
\hline (b) Males present aged $20-64$ & & & & & & \\
\hline No male & 45.6 & 43.3 & 27.4 & 36.8 & 27.3 & 35.7 \\
\hline 1 male present & 46.4 & 44.4 & 54.6 & 44.7 & 54.5 & 49.2 \\
\hline 2 males present & 5.2 & 7.2 & 8.7 & 15.2 & 11.5 & 9.7 \\
\hline 3 males present & 1.7 & 2.1 & 8.5 & 1.7 & 5.3 & 3.9 \\
\hline $4+$ males present & 1.1 & 3.0 & 0.8 & 1.6 & 1.4 & 1.5 \\
\hline $\begin{array}{l}\text { (c) Sex of head } \\
\text { Male head }\end{array}$ & & & & & & \\
\hline Male head & 47.2 & 49.1 & 54.6 & 61.9 & 67.8 & 57.0 \\
\hline Female head & 51.1 & 49.2 & 41.5 & 36.6 & 28.5 & 40.6 \\
\hline Not ascertained & 1.8 & 1.7 & 3.8 & 1.5 & 3.7 & 2.5 \\
\hline (d) Household size & & & & & & \\
\hline $1-2$ members & 5.5 & 10.2 & 5.7 & 11.0 & 23.5 & 11.9 \\
\hline 3-5 members & 23.8 & 33.5 & 26.1 & 28.8 & 30.1 & 28.3 \\
\hline $6-9$ members & 47.3 & 36.1 & 47.1 & 34.4 & 32.3 & 39.2 \\
\hline $10-14$ members & 19.2 & 15.1 & 17.3 & 21.8 & 11.9 & 16.9 \\
\hline $15+$ members & 4.3 & 5.2 & 3.8 & 4.0 & 2.2 & 3.7 \\
\hline Mean number of members & 7.5 & 6.6 & 7.2 & 6.8 & 5.7 & 6.7 \\
\hline (e) Number of children aged $0-14$ & & & & & & \\
\hline No children & 7.0 & 13.4 & 8.8 & 11.2 & 24.0 & 13.5 \\
\hline $1-3$ children present & 42.3 & 40.1 & 45.9 & 40.9 & 41.2 & 42.0 \\
\hline 4-6 children present & 36.7 & 34.4 & 37.6 & 34.2 & 27.0 & 33.6 \\
\hline $7+$ children present & 14.0 & 12.1 & 7.8 & 13.7 & 7.8 & 11.0 \\
\hline Mean number of children & 4.0 & 3.5 & 3.5 & 3.5 & 2.7 & 3.4 \\
\hline Children per adult & 1.2 & 1.1 & 0.9 & 1.1 & 0.9 & 1.0 \\
\hline
\end{tabular}

*Poverty Income Ratio (PIR) is the percentage of the household's Gross Available Income (GAI) to its Poverty Datum Line (PDL), which is defined as the 'basic minimum needed for a decent standard of living' (RIDS, p. 211 ).

$\dagger$ The Household Typology describes household composition by individuals of certain designated age-sex categories:

$\mathrm{E}=$ elderly person present over 65 years old

$M=$ male present aged $20-64$ years

$\mathrm{F}=$ female present aged $20-64$ years

$\mathrm{YD}=$ young dependent of either sex aged $0-19$ years.

$\$$ No male present of prime working age, 20-64 years old.

$\S$ Various household compositions including E-YD, E-M, E-F, E-M-YD, E-M-F, M-YD, M-F.

own somewhat more property than otherwise similar households, especially more cattle.

Table 2(b) further illustrates the association between the number of males aged 20-64 in the household and the PIR ratio. Among those households which are clearly below the poverty line (i.e., the two lowest PIR groups) over $43 \%$ have to manage without a permanent source of male labour. Table $2(\mathrm{c})$ focuses on a related demographic characteristic - female headedness.
A similar pattern is evident. In the lowest PIR groups $51 \%$ are female headed, and this percentage drops progressively to 29 in the highest PIR group. While the lack of a male of prime working age often is associated with female headship, these two phenomena, both resulting from the high rural out-migration rate, do not fully coincide. 5

Table 2(d) relates the number of people in the household to the household's ability to meet 
consumption needs. The table reveals a negative relationship between family size and income sufficiency. That is, larger families find it more difficult to produce or earn enough to stay out of poverty than do smaller ones. One difference between larger and smaller households lies in the number of children they have. Table 2(e) indicates that the PIR ratio is negatively related to the number of children aged $0-14$ and to the ratio of children $(0-14)$ per adult. Two opposing influences seem to be reflected here. On the one hand, fertility data for rural Botswana cxhibit a slight tendency for women who are relatively well off to have somewhat higher fertility than poorer women, ${ }^{6}$ and their children probably have a higher survival rate. We might expect a positive relation between household income and number of children for these reasons. However, young children tend to add to consumption needs without contributing commensurately to income. Thus the presence of numerous young children depresses the household's PIR. The reverse may be true for older children.

In brief, the demographic profile of the poor differs somewhat from the demographic profile of the higher PIR groups: poor households are more likely to lack a male of prime working age, to be headed by a woman, and to have a large number of children under 15 .

Table 3 describes PIR groups in terms of educational and locational characteristics. Two measures of education are employed, the highest education attained by any person over 15 in the household and the education of the head of household (Tables 3(a) and 3(b)). The proportion of households without any literate adult declines with rising PIR status as does the proportion of households with an illiterate head. Conversely, the presence of a person or head with 10 years or more of schooling rises sharply with PIR status; the cconomic advantage of having 5-9 years of education seems to be much more modest. In all, it would seem that, while having no education does not condemn a household to poverty, having a high level of education greatly enhances its chances of an adequate income.

Table 3(c) indicates that large villages offer a somewhat more favourable economic environment than small villages. Particularly in the highest PIR group, location in large villages is more frequent than in the sample as a whole; the reverse is true for location in small villages. Baralong Farms comprise a commercial cropping area where households are relatively well off.

Next we compare ownership of productive assets among the five PIR groups. Table 4(a) shows the distribution of cattle holdings, the most important asset in rural Botswana. The relationship is in the expected direction: poor households own far less cattle than the betteroff households. The strength of the relationship, however, is surprising. The proportion of households owning no cattle at all declines sharply from $80 \%$ in the lowest PIR groups to $18 \%$ in the highest. Eight to ten heads of cattle are usually considered necessary for ploughing. In the two lowest PIR groups over $90 \%$ of households own less than 10 heads of cattle; in the

Table 3. Distribution of households by education and location within PIR groups

\begin{tabular}{lcccccr}
\hline & & \multicolumn{5}{c}{ Poverty Income Ratio } \\
& $0-49 \%$ & $50-74 \%$ & $75-99 \%$ & $100-149 \%$ & $150+\%$ & All \\
\hline & $\%$ & $\%$ & $\%$ & $\%$ & $\%$ & $\%$ \\
(a) Highest education & & & & & & \\
No education & 36.9 & 31.9 & 23.6 & 23.1 & 21.9 & 27.3 \\
1-4 years & 30.0 & 34.6 & 34.3 & 35.0 & 23.0 & 30.6 \\
$5-9$ years & 29.6 & 27.0 & 30.8 & 30.5 & 34.2 & 30.7 \\
10+ years & 3.6 & 6.5 & 11.3 & 11.5 & 21.0 & 11.3 \\
(b) Education of head & & & & & & \\
No education & 67.3 & 62.9 & 59.4 & 64.1 & 48.9 & 59.9 \\
1-4 years & 22.1 & 26.5 & 28.2 & 18.5 & 16.8 & 21.8 \\
5-9 years & 4.4 & 4.0 & 3.1 & 9.4 & 17.3 & 8.4 \\
10+ years & 0.0 & 0.0 & 0.0 & 0.9 & 8.2 & 2.3 \\
Not ascertained & 6.2 & 6.6 & 9.3 & 7.1 & 8.9 & 7.7 \\
(c) Location of household & & & & & & 81.9 \\
Small village & 86.1 & 80.6 & 88.5 & 83.1 & 73.8 & 2.6 \\
Baralong farm & 0.0 & 2.2 & 1.6 & 4.1 & 4.8 & 15.4 \\
Large village & 13.9 & 17.3 & 9.9 & 12.8 & 21.4 & \\
\hline
\end{tabular}


Table 4. Distribution of households by asset holdings within PIR groups

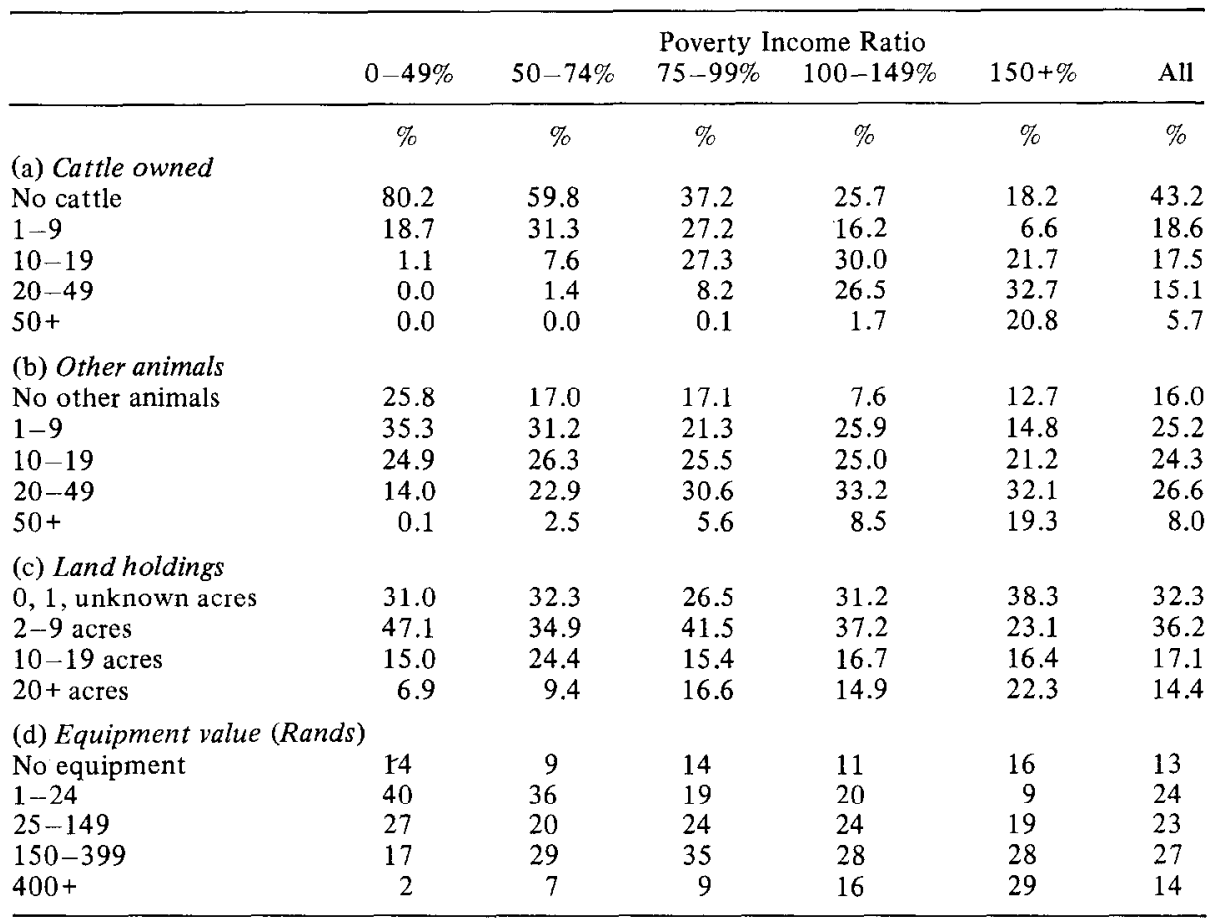

highest PIR groups threc-fourths of houscholds have 10 heads of cattle or more; the majority having more than 20 heads.

Ownership of smaller animals such as goats, sheep, pigs and poultry is more widespread than cattle ownership (Table 4(b)). Eighty-four percent of houscholds own some small stock, compared with only $57 \%$ who own cattle. Also small stock is more equally distributed than are larger animals. Nevertheless, it is interesting that ownership of small stock increases with income status. Thus, any notion that poorer households are able to raise more small stock than the wealthier ones to compensate for their lack of cattle is not substantiated.

Table 4(c) refers to land holdings. Presumably land is allocated to households by the tribal authorities according to need and to ability to cultivate it. Since in a fair number of cases size of land holdings was not ascertained, we cannot determine how many households did not cultivate any land at all. It is clear, however, that small holdings ( $2-9$ acres) predominate in the lower and middle PIR groups, while large land holdings ( 20 acres or more) are associated with higher PIR status. Evidently owners of substantial cattle herds have an advantage in ploughing large areas of land. In addition, considcrations of political and cconomic status may affect the land allocation process to some extent. Still, inequalities in land holdings are small compared with inequalities in cattle holdings. Many households in the two lowest PIR groups have no cattle but cultivate at least a modest amount of land. They must hire ploughing services or receive help with ploughing from relatives.

Finally, we may examine the distribution of productive equipment among PIR groups. Equipment includes such items as agricultural implements and machinery, carts, wheelbarrows, water tanks, guns, and some business equipment. Such items of equipment, like other productive assets, increase in number and value with rising PIR status. Indeed, the difference in equipment ownership between the two extreme PIR groups is very pronounced.

The reader will note that there are a few wellto-do households (about 10-15\% of groups IV and $V$ ) which do not seem to own cattle or other productive assets. These households earn adequate incomes in wage jobs or other occupations which do not require personal ownership of the kind of assets enumerated here.

In concluding this section, it should be pointed out that the relationships depicted in 
Tables 2-4 do not speak to causality. For example, the top PIR group may have a comfortable income because it has large holdings of productive assets. At the same time, an income in excess of subsistence needs enables a household to acquire additional productive assets. Both kinds of influences are likely to be at work.

\section{TIME USE AND SOURCES OF INCOME}

The economic activities of poor and better-off households will now be compared by examining their sources of income and patterns of time use. RIDS identified 10 sources of income: crops, animal husbandry, wage employment, manufacturing (food processing, leather tanning, etc.), trading and vending, services and construction, hunting and fishing, gathering, transfers and property. In the discussion and tables which follow, net primary income (gross current receipts minus production expenses and depreciation) is used for the first eight sources of income. For transfer and property income only data on gross current receipts are available; that is, we have no measure of income transfers out of the household. The income data include income in cash and kind.

The frequency with which each income source was reported varies considerably. In the sample at large, $96 \%$ of households report income from gathering, while $12 \%$ report trading and vending income. Table 5 indicates the percentage of households reporting each type of income within each PIR group. For example, $89 \%$ of all households in the lowest PIR group reported crop income. It is interesting to note that the average household received income from five to six sources. Almost every household engaged in crop and animal husbandry and gathering and almost all households received transfer income. In addition the majority of households received income from services and construction and half of all households had wage employment at some time during the year. This pattern of involvement is quite similar for all income groups. It should be noted that among the poorer households income from crops and livestock is reported morc often than ownership of land and animals. This income presumably is obtained by working for others, most commonly members of the extended family or clan.

Three inferences may be drawn from Table 5: (1) Most rural households piece together a living by engaging in a variety of income earning activities rather than specializing in one or two. (2) Regardless of income, households try to be fairly self-sufficient. They raise at least part of their own food (or obtain it by helping other households with crop or animal husbandry), and they gather wood and wild food. (3) Receipts of gifts and other transfer income are very widespread, suggesting a high degree of reciprocity rather than an exclusive pattern of transfers from better-off to poor.

Table 6 focuses on the distribution of income by source. It reveals striking differences in the relative importance of the income sources among PIR groups. While animal husbandry accounts for $52 \%$ of the top PIR group's income and transfers contribute only $8 \%$, among the poorest

Table 5. Percentage of households reporting income from various sources by poverty income ratio groups

\begin{tabular}{|c|c|c|c|c|c|c|}
\hline Income source & $0-49 \%$ & $50-74 \%$ & $\begin{array}{l}\text { Poverty } \\
75-99 \%\end{array}$ & $\begin{array}{l}\text { come Ratio } \\
100-149 \%\end{array}$ & $150+\%$ & All \\
\hline & $\%$ & $\%$ & $\%$ & $\%$ & $\%$ & $\%$ \\
\hline Crops & 89.3 & 84.4 & 93.0 & 91.1 & 87.2 & 89.0 \\
\hline Animal husbandry & 82.2 & 88.9 & 95.4 & 94.0 & 91.5 & 90.2 \\
\hline Wage employment & 62.9 & 47.0 & 45.1 & 43.0 & 48.0 & 49.7 \\
\hline Manufacturing & 74.7 & 78.2 & 69.1 & 72.7 & 48.6 & 67.2 \\
\hline Trading and vending & 7.9 & 15.1 & 10.5 & 14.8 & 10.6 & 11.5 \\
\hline Services and construction & 51.8 & 47.4 & 64.2 & 60.2 & 49.3 & 65.8 \\
\hline Hunting and fishing & 10.9 & 6.9 & 10.5 & 14.0 & 24.5 & 14.3 \\
\hline Gathering & 98.2 & 97.7 & 96.8 & 98.0 & 90.2 & 95.8 \\
\hline Transfers & 95.5 & 97.1 & 92.0 & 93.4 & 88.2 & 92.9 \\
\hline Property* & 0.0 & 0.0 & 0.0 & 0.5 & 0.2 & 0.1 \\
\hline Percentage of sample & 22.2 & 15.5 & 17.2 & 19.6 & 25.5 & 100.0 \\
\hline
\end{tabular}

*Property income covers only income from financial assets, which are uncommon in rural areas. Income from cattle is reported under cattle income; income from a business under trading or manufacturing, etc. 
Table 6. Distribution of income from various sources by Poverty Income Ratio groups

\begin{tabular}{lrrrrr}
\hline \multicolumn{1}{c}{ Income source } & \multicolumn{5}{c}{ Poverty Income Ratio } \\
& $0-49 \%$ & $50-74 \%$ & $75-99 \%$ & $100-149 \%$ & $150+\%$ \\
\hline & $\%$ & $\%$ & $\%$ & $\%$ & $\%$ \\
Crops & 16.2 & 14.8 & 12.5 & 9.5 & 9.7 \\
Animal husbandry & 5.9 & 21.3 & 37.5 & 48.6 & 51.8 \\
Wage employment & 11.7 & 14.2 & 15.2 & 16.2 & 22.7 \\
Manufacturing & 9.1 & 10.9 & 5.9 & 3.1 & 1.5 \\
Trading and vending & 0.4 & 4.6 & 1.8 & 0.8 & 0.9 \\
Services and construction & 4.7 & 2.0 & 3.6 & 2.4 & 1.9 \\
Hunting and fishing & 2.2 & 0.5 & 1.1 & 2.0 & 1.1 \\
Gathering & 17.8 & 10.4 & 8.0 & 5.5 & 2.4 \\
Transfers & 32.0 & 21.4 & 14.4 & 12.0 & 7.9 \\
Property & 0.0 & 0.0 & 0.0 & 0.06 & 0.0 \\
Total & 100.0 & 100.0 & 100.0 & 100.0 & 1.00 .0 \\
Mean income (in Rands) & 207 & 347 & 555 & 729 & 1616 \\
\hline
\end{tabular}

households transfer income constitutes $32 \%$ of total income while animal husbandry provides only $6 \%$. There is a strong positive relation between PIR status and reliance on wage employment and animal husbandry. The poorest earn $12 \%$ of their income from wage cmployment; this percentage rises to $23 \%$ for the most affluent households who perform more skilled work and carn higher wages. The small contribution of wages to the income of poor households reflects the dearth of opportunities for wage work, cspecially in crop cultivation, as compared to many other developing countries. ${ }^{7}$ As noted earlier, the importance of animal husbandry income rises dramatically from $6 \%$ for the poorest to $52 \%$ for the top income households. On the other hand there is a negative relation between PIR status and the proportion of income derived from crops, manufacturing, gathering and transfers. Trading and vending, hunting and fishing, and scrvices and construction are of minor importance for all income groups; such sources each account for less than $5 \%$ of total income.

In sum, our PIR groups have very different income by source profiles. The poorest rely on transfers and crops for half of their total income, whereas the wealthiest households receive half of their income from animal husbandry.

While percentage distributions give an indication of reliance on various income sources, a more complete picture evolves when one compares mean incomes from each source. The mean incomes were determined by dividing the sum of income from each source for each PIR group by the weighted number of households reporting that source in that PIR group. The results are presented in Table 7 . In absolute amounts the poor receive less income from every source than do the better-off households. For instance, while cropping accounted for $16 \%$ of the poor's income and amounted to 38 Rands annually per household engaged in crop production, the wealthiest relied on crops for only $10 \%$ of their income, but received 182 Rands per participating household. The story is repeated for transfer income: transfers accounted for $32 \%$ of the poorest households' income, but this amounts annually to only 70 Rands per household receiving transfers. The wealthiest households depended on transfer receipts for only $8 \%$ of their total net income, but on average obtained 145 Rands annually per receiving household.

The indices presented in the lower part of Table 7 further illustrate the disparities associated with various income sources. These indices were constructed by setting the top PIR group's mean income from each source equal to 100 . Thus, within each income source, the proportion of the lower PIR groups' income relative to the income of the top group can be seen easily. The index for the total of all sources of income shows that the two poorest groups receive 13 and $31 \%$ respectively of the average income of the top group. It is evident that a large part of the overall disparity is caused by the very unequal distribution of income from crops, animal husbandry and wage employment. $\Lambda 11$ three are activities in which between two-thirds and nine-tenths of the poorest households participate. (We shall later compare the number of hours of participation.) Other types of income are more equally distributed or are unimportant.

The real income disparity between rich and poor would be narrowed if large households were in the higher PIR groups. Our demographic analysis, however, indicated the opposite to be 
Table 7-A. Mean household income (in Rands) from various sources by Poverty Income Ratio groups*

\begin{tabular}{lccccc}
\hline \multirow{2}{*}{ Income source } & \multicolumn{5}{c}{ Poverty Income Ratio } \\
& $0-49 \%$ & $50-74 \%$ & $75-99 \%$ & $100-149 \%$ & $150+\%$ \\
\hline & $\mathrm{R}$ & $\mathrm{R}$ & $\mathrm{R}$ & $\mathrm{R}$ & $\mathrm{R}$ \\
Crops & 37.50 & 60.76 & 74.64 & 75.75 & 181.66 \\
Animal husbandry & 14.82 & 82.97 & 218.65 & 377.48 & 924.53 \\
Wage employment & 38.55 & 105.17 & 186.49 & 274.07 & 773.51 \\
Manufacturing & 25.26 & 48.40 & 47.37 & 31.18 & 51.38 \\
Trading and vending & 11.17 & 106.31 & 95.50 & 38.09 & 135.72 \\
Service and construction & 18.90 & 14.40 & 30.97 & 29.13 & 63.59 \\
Hunting and fishing & 42.10 & 26.21 & 57.36 & 101.62 & 75.84 \\
Gathering & 37.59 & 36.75 & 46.07 & 41.24 & 43.51 \\
Transfer & 69.54 & 76.40 & 86.89 & 93.46 & 145.27 \\
Property & 0 & 0 & 0 & 8.38 & 4.00 \\
\hline
\end{tabular}

*Mean income calculated including only households reporting that source of income.

Table 7-B. Index of mean incomes from various sources by Poverty Income Ratio groups (Mean Income of $150+\%$ PIR Group $=100$ for each income source)

\begin{tabular}{lrrrrr}
\hline \multicolumn{1}{c}{ Income source } & $0-49 \%$ & $50-74 \%$ & $75-99 \%$ & $100-149 \%$ & $150+\%$ \\
\hline Crops & 21 & 33 & 41 & 42 & 100 \\
Animal husbandry & 2 & 9 & 24 & 41 & 100 \\
Wage employment & 5 & 14 & 24 & 35 & 100 \\
Manufacturing & 49 & 94 & 92 & 61 & 100 \\
Trading and vending & 8 & 78 & 70 & 28 & 100 \\
Service and construction & 30 & 23 & 49 & 46 & 100 \\
Hunting and fishing & 56 & 35 & 76 & 134 & 100 \\
Gathering & 86 & 85 & 106 & 95 & 100 \\
Transfers & 48 & 53 & 60 & 64 & 100 \\
Property & 0 & 0 & 0 & 210 & 100 \\
All sources & 13 & 21 & 34 & 45 & 100 \\
\hline
\end{tabular}

the case: there is some tendency for large households to be in the lower PIR groups, although the extra number of children in the poorer households is greater than the extra number of adults (Tables 2(d) and 2(e)). On a per person basis the gap between rich and poor is widened. Indexes of inequality on a per person basis are presented in Table 8 .

Conceivably the dissimilarity of the income by source profiles for well-to-do and poor households, as well as the disparity between the highest and lowest incomes, reflects different patterns of time use. To wit, one reason why the rich receive more from crops, animal husbandry and wage employment may be that they spend more of their time in these pursuits. This is only a partial explanation, however. The overall time use patterns do not vary greatly among PIR groups as can be seen in the distribution of activity time for each PIR group by age and sex in Tables 9-A and 9-B. To be sure, the percent- age of time spent on all income earning activities by adult males rises with PIR status from $25 \%$ for the poorest group to $34 \%$ for the wealthiest, a considerable difference. ${ }^{8}$ Yet wage labour accounts for most of this differential in working time. The poorest adult males devote $2 \%$ of their time to wage labour; this rises steadily to $11 \%$ in the highest PIR group. The time allocation of boys and young males shows some tendency for income earning time to rise with PIR status, although there is a reversal in the top PIR groups, where schooling occupies more time. PIR status does not seem to be related to the working time of girls and women. In sum, only a small part of the large income disparity between rich and poor can be accounted for by differences in labour utilization.

A further explanation of income inequalities is that there are differences in the composition of time contribution by age/sex categories between PIR groups. That is, where a large 
Table 8. Index of income per person from various sources by Poverty Income Ratio groups

\begin{tabular}{|c|c|c|c|c|c|}
\hline \multirow[b]{2}{*}{ Income source } & \multicolumn{5}{|c|}{ Poverty Income Ratio } \\
\hline & $0-49 \%$ & $50-74 \%$ & $75-99 \%$ & $100-149 \%$ & $150+\%$ \\
\hline Crops & 16 & 30 & 34 & 36 & 100 \\
\hline Animal husbandry & 1 & 8 & 19 & 34 & 100 \\
\hline Wage employment & 4 & 11 & 19 & 31 & 100 \\
\hline Manufacturing & 39 & 85 & 78 & 53 & 100 \\
\hline Trading and vending & 5 & 58 & 51 & 30 & 100 \\
\hline Service and construction & 23 & 18 & 42 & 37 & 100 \\
\hline Hunting and fishing & 46 & 36 & 56 & 98 & 100 \\
\hline Gathering & 70 & 77 & 90 & 83 & 100 \\
\hline Transfer & 38 & 48 & 49 & 57 & 100 \\
\hline Property & 0 & 0 & 0 & 156 & 100 \\
\hline
\end{tabular}

portion of reported income earning time is contributed by women and children, the income earned might be lower on that account. Table 10 presents the relative contribution of income earning timc by agc and scx for each PIR group and reveals the expected differentials; the relative importance of adult male inputs increases with PIR status. Where adult males provide $22 \%$ of the hours devoted to income earning in the lowest PIR group, they account for $42 \%$ of the labour hours in the highest PIR classification. We saw earlier that there is a relatively high proportion of households without a male of prime working age in the lower PIR groups.

The major explanation for the wide gap between high and low income households is that members of the higher PIR groups produce more income per unit of working time. To derive an estimate of the average output per unit of labour we divided the income from each source by the working time reported for that source. For expositional simplicity the results are presented in an indexed form in Table 11, where the earnings per unit of time of the highest PIR group in wage employment are set equal to 100 . The index measures the average productivity for other economic activities and PIR groups relative to this numeraire. As would be anticipated from previous findings, the index for the top PIR group in animal husbandry is very high: 93. More surprising perhaps is the high index value in the top PIR group for the income category manufacturing, trading, vending and services. Our earlier results indicate that these income sources are of minor importance to the well-to-do; yet when we take into account the amount of time devoted, these are relatively productive activities for higher PIR households. Quite clearly, the assets and education with which the higher PIR groups are endowed enhance their earnings in many diverse areas. It is interesting that even in crop husbandry, hunting, fishing and gathering, the poor earn much less per unit of working time than the well-to-do.

Another interesting point is that for the two top income groups, crop husbandry and hunting, fishing and gathering are much less rewarding occupations than animal husbandry, wage employment, manufacturing, trading and services. Why then do the upper income groups pursue these economic activities at all? The most likely explanation is that work opportunities in the more rewarding occupations are quite limited, being constrained by the capital available to buy cattle and other productive assets, by the size of the local market, and by the demand for educated wage labour (largely government jobs). Thus, in the more rewarding occupations a point may be reached where additional inputs of labour would not be productive. Conscquently a part of the available labour time in the higher income households is devoted to the less remunerative occupations. Another explanation is that in order to assure themselves of an adequate food supply, almost all households participate in crop production, gathering, and hunting. Most likely these are complementary rather than alternative explanations.

Likewise, there are a number of possible explanations for the large difference in labour productivity between the rich and poor. The first and most important is that the PIR groups have different access to productive asse is: the farmers in the top PIR group have more or better land, cattle for ploughing, or may even be working with a tractor while workers in the bottom PIR group may have only simple tools and may have to rely on other people's cattle for ploughing. In the extreme case the poor may be working for the larger land and cattle owners. The endowment of productive assets by PIR 

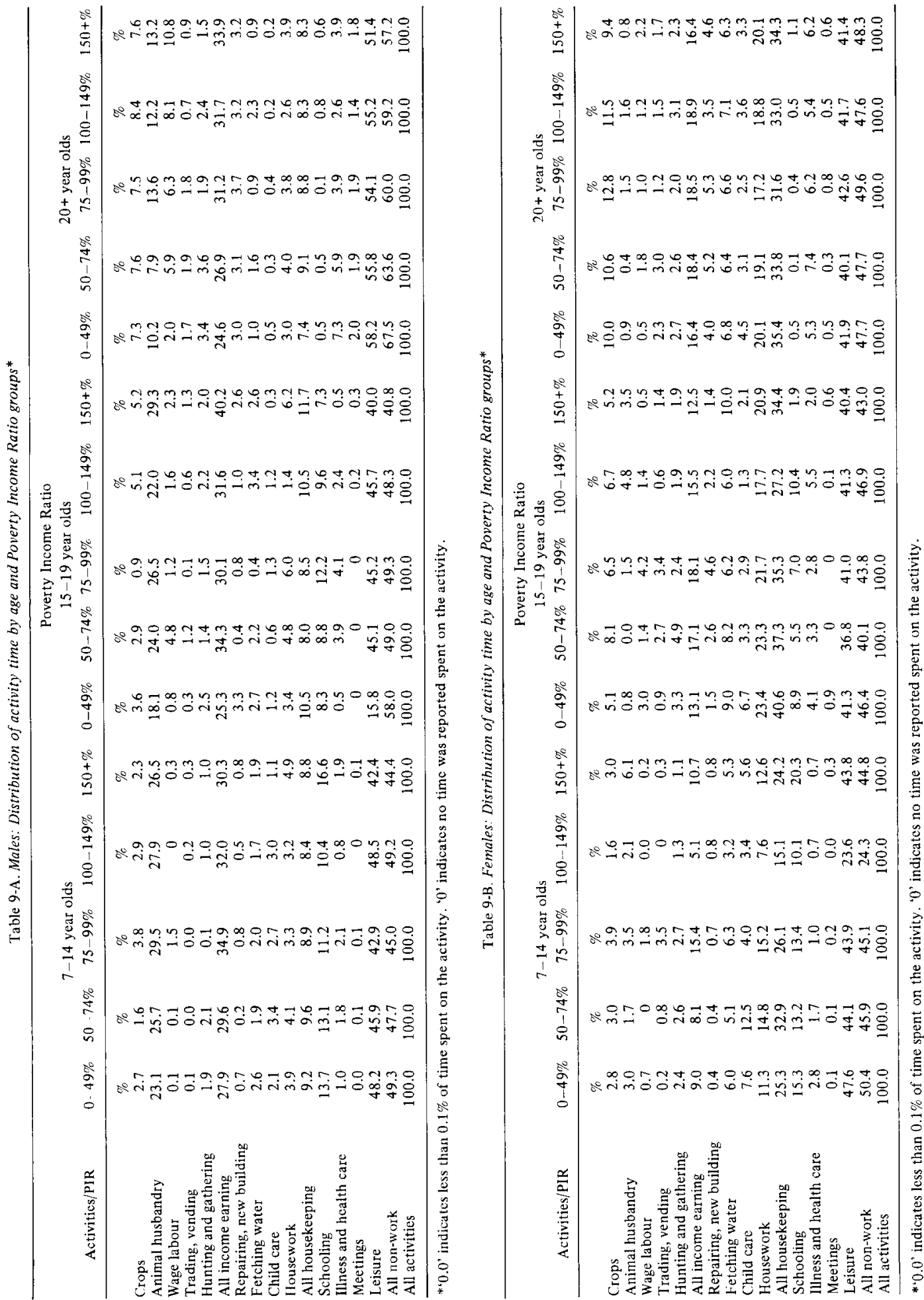
Table 10. Relative contribution of income earning time from different age and sex groups by Poverty Income Ratio groups

\begin{tabular}{lccccc}
\hline \multicolumn{5}{c}{} & \multicolumn{5}{c}{ Poverty Income Ratio } \\
& $0-49 \%$ & $50-74 \%$ & $75-99 \%$ & $100-149 \%$ & $150+\%$ \\
\hline Males & $\%$ & $\%$ & $\%$ & $\%$ & $\%$ \\
$7-14$ & 22.1 & 23.2 & 23.8 & 24.5 & 16.6 \\
$15-19$ & 6.5 & 10.2 & 8.1 & 6.9 & 8.1 \\
$20+$ & 21.7 & 24.3 & 29.2 & 30.8 & 41.9 \\
Females & & & & & \\
$7-14$ & 9.6 & 7.2 & 7.8 & 5.6 & 6.6 \\
$15-19$ & 6.3 & 6.2 & 5.0 & 5.3 & 3.3 \\
$20+$ & 33.9 & 28.9 & 26.1 & 26.9 & 23.4 \\
Total & 100.0 & 100.0 & 100.0 & 100.0 & 100.0 \\
\hline
\end{tabular}

Table 11. Index of earnings per unit of time from various sources by Poverty Income Ratio groups*

\begin{tabular}{lccccc}
\hline & \multicolumn{5}{c}{ Poverty Income Ratio } \\
\multicolumn{1}{c}{ Income source } & $0-49 \%$ & $50-74 \%$ & $75-99 \%$ & $100-149 \%$ & $150+\%$ \\
\hline Crops & 4 & 7 & 8 & 8 & 26 \\
$\begin{array}{l}\text { Animal husbandry } \\
\text { Wage }\end{array}$ & 2 & 9 & 17 & 30 & 93 \\
$\begin{array}{l}\text { Manufacturing, trade, } \\
\text { vending and service }\end{array}$ & 21 & 21 & 28 & 42 & 100 \\
$\begin{array}{l}\text { Hunting, fishing and } \\
\text { gathering }\end{array}$ & 20 & 31 & 47 & 53 & 78 \\
\hline
\end{tabular}

*Index: Earnings per unit of time from wage labour in the $150+\%$ PIR group equals 100 .

status has been presented in Table 4 and was discussed previously.

Second, there are educational differences. Having more education, the rich may be able to parlay their greater knowledge, know-how, and skills into higher productivity, particularly wellpaying wage jobs.

Third, economies of scale may exist, especially in animal husbandry and cropping. It probably does not take much more labour to herd or market 50 heads of cattle than 15 .

Fourth, one must question whether the large differentials in income per unit of work time could reflect errors in the reporting of income or time use. As regards income, it has generally been found that in household surveys income is underreported. There is no evidence however to suggest that poor households underreport their income to a greater extent than well-to-do households; if anything, the opposite should be expected. Much less is known about possible biases in the reporting of time use. There are indications that in rural Botswana time spent in minor activities was underreported. A person who owns a large herd of cattle may be less prone to recall time spent hunting or doing construction work. On the other hand, a person who has claim to few animals and little land which make demands on his time will be less likely to ignore labour time spent in such peripheral activities as hunting, gathering, or odd jobs. Thus there may be an underreporting of the time spent on trading and vending, hunting and fishing, gathering, and services and construction by the richer households which would inflate their calculated productivity per unit time in these less important activities.

Finally, our estimates of working time give no indication of the intensity of effort. ${ }^{9}$ It is conceivable that poor people work in a more leisurely fashion and take more rest breaks. They are probably undernourished; their work is less productive and there may be little pressure to finish a job quickly when few other work possibilities are available which would increase income significantly. In other words, the labour of the poor may be more under-utilized than the labour of households with larger asset hold- 
ings. If the working time of the poor were overestimated, their productivity per unit of time actually worked would be underestimated.

A further distinction between the poor and better-off households in rural areas concerns their relation to the monetized economy. To analyse this relation we separately considered gross current receipts and production expenses. Table 12 presents gross current receipts in kind as a percentage of total gross current receipts by income source and PIR status. useful in that they provide information about the demographic and economic characteristics of poverty groups so that policies to aid them can be properly designed. Our analysis suggests that disparities in income among households are associated less with differences in inputs of income-earning time than with differences in access to productive assets, educational attainment, and availability of male labour. In addition, poor households are more likely than others to be confined to the non-monetized sector.

Table 12. Percent of receipts from various income sources received in kind by Poverty Income Ratio groups

\begin{tabular}{lrrrrr}
\multicolumn{1}{c}{ Income source } & $0-49 \%$ & $50-74 \%$ & $75-99 \%$ & $100-149 \%$ & $150+\%$ \\
\hline Crops & 94 & 90 & 93 & 83 & $6 \dot{4}$ \\
Animal husbandry & 77 & 70 & 71 & 69 & 63 \\
Wage employment & 37 & 9 & 9 & 5 & 3 \\
Manufacturing & 2 & 2 & 9 & 5 & 1 \\
Trading and vending & 2 & 4 & 2 & 1 & 1 \\
Service and construction & 56 & 39 & 66 & 48 & 16 \\
Hunting and fishing & 70 & 85 & 67 & 70 & 66 \\
Gathering & 96 & 99 & 91 & 95 & 90 \\
Transfer & 41 & 40 & 33 & 27 & 10 \\
Property & 0 & 0 & 0 & 0 & 0 \\
\hline
\end{tabular}

Clearly, the poor rely more heavily on in-kind receipts for crop, animal husbandry, services and construction, as well as wage and transfer income. It is noteworthy that while the poor receive $37 \%$ of their payments for wage labour in kind, the wealthiest households receive only $3 \%$ in kind. Transfer receipts likewise are increasingly in kind with lower PIR status. Trading and vending is transacted almost entirely in cash. In the areas of manufacturing, hunting, fishing and gathering there is little relation between the percentage received in kind and PIR status.

If we conjecture that in-kind receipts may underestimate the value of goods or services rendered, then the income disparity between rich and poor may be slightly smaller than the data indicate. At the same time it is clear that the well-to-do operate in the monetized economy to a greater extent than the poor; and the monetized economy is more productive, and hence more rewarding, than the subsistence economy. There are no corresponding differentials as regards payments for inputs.

\section{CONCLUSIONS}

The Government of Botswana is committed to the alleviation of poverty. Poverty profiles are
These conclusions do not imply that the poor have adequate employment opportunities. Adult males in the poorest households have significantly less market work, especially wage work, than men in other households. We also conjectured that the working time of the poor may be overstated by the time use data. That is, the low productivity of the poor and the relatively modest demands on their time may lead them to adopt a slower work pace than better situated workers. Michael Lipton, after an intensive analysis of labour utilization in Botswana, concluded that there is a $45 \%$ underutilization of labour in that economy. ${ }^{10}$ The precision of that estimate is not important for our purposes. The point is that low working hours, low productivity, and low work intensity are intimately related. All three reflect the insufficiency of productive assets available to the poor, their frequent illiteracy, a high ratio of female headed households among them, and their attachment to the subsistence economy.

The objective of reducing poverty often is associated with the idea of redistributing income (or supplementing income). The Botswana poverty profile underlines the fact that the basic problem of rural poverty is the maldistribution of assets, or the insufficiency of assets (including human capital) available to the lowest 
income groups. It follows that, in addition to promoting land reform, governments must find ways of providing the lowest income groups with productive assets by means of subsidized credit programmes and programmes which enable the poor to lease assets (such as a team of oxen) at moderate cost. Furthermore, the poor must be induced to send their children to school and must be provided with instruction in agriculture and with vocational training. Access to rural wage employment can break the linkage between personal asset ownership and productivity and hence needs to be expanded.

Finally, in rural areas with a high level of male out-migration, female headed houscholds must be made a special target of government assistance.

\section{NOTES}

1. For a further discussion of this approach see Hollis Chenery et al., Redistribution with Growth (London: Oxford University Press, 1974), pp. 1926 and $237-40$.

2. The response rate for RIDS was about $90 \%$ after eliminating about 100 households for which data were too incomplete to merit retention in the sample. This is a much higher response rate than is usually obtained in household surveys in Western Europe or the US. However, there remained in the sample a fair number of cases where one or more sources of income were not reported for all twelve rounds or time use for all 5 rounds. In the case of gaps in the income data, income received in a prior month by the same household was substituted for the missing income, taking care to select a month without large unusual sources of income. In the case of gaps in the time use data, average time use by that same household was calculated for the completed rounds and substituted for the missing round(s). The important point here is that we avoided estimating missing data on the basis of demographic or socioeconomic characteristics in order to protect the integrity of the subsequent data analysis by such characteristics. The most difficult part of the data editing concerned household composition, which is quite fluid in Botswana, with a good deal of short term movement. It suffices to report here that after careful checking on a case by case basis, recoding, and numerous adjustments, average houselíold size and the age/sex composition of the sample conform reasonably well with the 1971 Botswana Census.

3. Central Statistical Office, Government of
Botswana, The Rural Income Distribution Survey in Botswana, 1974-75, Appendix 15.

4. Seminar conducted in Gaborone, Botswana, on June 26-28, 1979.

5. See Sherrie Kossoudji and Eva Mueller, 'The economic and demographic status of female headed households in Botswana', Economic Development and Cultural Change (July 1983), pp. 831-859.

6. See Dov Chernichovsky, 'Socio-Economic Correlates of Fertility Behavior in Rural Botswana' (World Bank, 1979, mimeographed).

7. See Robert E. B. Lucas, 'The Distribution of Wages and Employment in Rural Botswana', Population and Human Resources Division, Discussion Paper No. 81-46 (Washington, D.C.: World Bank, 1981).

8. Time devoted to income earning activities may be somewhat underestimated overall because shortduration activites were sometimes forgotten.

9. The collection of time use data is a relatively new undertaking. The problem of measuring work intensity is as yet unsolved.

10. Michael Lipton, Employment and Labour Use in Botswana, Final Report to Ministry of Finance and Development Planning (Botswana: December 1978). Professor Lipton served as Employment Development Advisor to the Government of Botswana. 